\title{
Comparison of oral and nasal immunization with inactivated porcine epidemic diarrhea virus on intestinal immunity in piglets
}

\author{
EN ZHANG, JIALU WANG, YUCHEN LI, LULU HUANG, YONGHENG WANG and QIAN YANG \\ MOE Joint International Research Laboratory of Animal Health and Food Safety, \\ College of Veterinary Medicine, Nanjing Agricultural University, Nanjing, Jiangsu 210095, P.R. China
}

Received July 1, 2019; Accepted February 20, 2020

DOI: $10.3892 /$ etm.2020.8828

\begin{abstract}
Porcine epidemic diarrhea virus (PEDV) has proven to be a major problem for the porcine industry worldwide. Conventional injectable vaccines induce effective systemic immune responses but are less effective in preventing PEDV at mucosal invasion sites, including the nasal or oral mucosa. Additionally, antigens delivered orally are easily degraded. Nasal immunization induces intestinal mucosal immune responses, which can aid in blocking viral invasion, and requires fewer antigen inoculation doses. Therefore, nasal immunizations are considered to be a potential approach to overcome viral infections. In the present study, nasal immunization of piglets was performed using inactivated PEDV combined with Bacillus subtilis as an immunopotentiator and the efficacy of nasal immunization was assessed. The results demonstrated that compared with oral immunization, piglets from the nasal immunization group exhibited higher levels of neutralizing antibodies $(\mathrm{P}<0.01)$ in the intestine, $P E D V$-specific immunoglobulin $(\mathrm{Ig}) \mathrm{G}(\mathrm{P}<0.01)$ in serum and $\mathrm{PEDV}$-specific secretory $\operatorname{IgA}(\mathrm{SIg} \mathrm{A})$ in saliva $(\mathrm{P}<0.01)$ and nasal secretions $(\mathrm{P}<0.01)$. An increased number of intestinal $\mathrm{CD}^{+} \mathrm{T}$ cells, IgA-secreting cells and intraepithelial lymphocytes $(\mathrm{P}<0.05)$ were also observed. Furthermore, the protein expression levels of interleukin- 6 and interferon- $\gamma$, relative to the control PEDV infection, were also significantly elevated $(\mathrm{P}<0.05)$. The results of the present study indicate that nasal immunization is more effective at inducing the intestinal mucosal immune response, and provide new insights into a novel vaccination strategy that may be used to decrease the incidence of PEDV infections.
\end{abstract}

Correspondence to: Professor Qian Yang, MOE Joint International Research Laboratory of Animal Health and Food Safety, College of Veterinary Medicine, Nanjing Agricultural University, 1 Weigang, Nanjing, Jiangsu 210095, P.R. China

E-mail: zxbyq@njau.edu.cn

Key words: porcine epidemic diarrhea virus, vaccine, nasal immunization, oral immunization, Bacillus subtilis

\section{Introduction}

Porcine epidemic diarrhea (PED) is an acute and highly contagious disease, which is characterized by vomiting, diarrhea, dehydration and a high mortality rate in neonatal piglets (1). PED was first observed in 1971 and caused substantial economic losses to the pig industry (2). As the causative agent, PED virus (PEDV) exclusively infects and replicates in the villous enterocytes of the small intestine (3). Currently available PEDV vaccines are administered via intramuscular or subcutaneous injection and induce a systemic immunoglobulin (Ig)G response (4). However, serum IgG is not effective in preventing PEDV infection in the intestinal mucosa $(4,5)$. Studies have demonstrated that secretory $\operatorname{IgA}(\operatorname{SIgA})$, a dominant antibody in the intestinal mucosal immune responses, inhibits the invasion of enteric pathogens (6). Consequently, determining how to induce the intestinal mucosal immune response and promote the production of SIgA in the intestinal mucosa is important for the prevention and control of PEDV.

Oral immunization has previously been considered to be an effective strategy for inducing intestinal mucosal immunity (7). However, a large quantity of the antigen is often lost due to gastric acid and protease-mediated degradation within the gastrointestinal tract, thereby leading to poor protection against PEDV infection (8). A recent study indicated that airborne transmission was a major route of PEDV invasion (9). Compared with oral immunization, nasal immunization is more convenient and may overcome the challenge of degradation or clearance. According to the theory of the common mucosal immune system, nasal vaccinations could induce immune responses not only in the local mucosal site but also in other mucosal sites (10). A previous study demonstrated that nasal vaccinations can generate $\operatorname{Ig} \mathrm{A}$ antibody-secreting cells and IgG antibody-secreting cells in the intestine $(11,12)$. Therefore, the nasal cavity may be a new target for inducing the intestinal mucosal immune response against PEDV infection.

Currently, a live-attenuated PED vaccine is used. Although live attenuated vaccines can induce a strong antibody response, live viruses are unsafe and risk reverting to a higher virulence (13). Inactivated viruses are safe but are usually not sufficiently effective in inducing the local immune responses that are necessary for preventing infectious diseases when used alone (14). Therefore, inactivated viruses often require an appropriate immunopotentiator 
capable of adequately strengthening the immune response. Bacillus subtilis (B. subtilis) is a gram-positive nonpathogenic and endospore-forming bacterium species that is prevalent worldwide (15). B. subtilis has been used as an additive when feeding animals in the pig industry (16). Previous studies have demonstrated that $B$. subtilis exhibits a significant immunopotentiating effect that leads to an enhanced mucosal immune response $(17,18)$.

In the present study, the immune responses after nasal immunization with inactivated PEDV combined with B. subtilis were evaluated in piglets. The results revealed that nasal immunization could induce the immune response in the local nasal mucosa and in the intestinal mucosa. Compared with oral immunization, piglets receiving nasal immunization exhibited higher SIgA levels and an increased number of immune cells in the intestine. The results of the present study demonstrate a convenient and effective strategy for PEDV prevention and provide information regarding the common mucosal immune system in pigs.

\section{Materials and methods}

Probiotics, virus and animals. The B. subtilis strain was maintained at $-70^{\circ} \mathrm{C}$ by the present laboratory. The strains were grown in Luria-Bertani broth containing $50 \mu \mathrm{g} / \mathrm{ml}$ kanamycin. PEDV Zhejiang08 strain was provided by the Veterinary Medicine Research Center (Beijing Da Bei Nong Science and Technology Group Co., Ltd.). This strain has been successfully attenuated and can induce a classical cytopathic effect in Vero E6 cells (19). PEDV was amplified in Vero cells in DMEM (Wisent Biotechnology) containing $2 \% \mathrm{FBS}$ at $37^{\circ} \mathrm{C}$ in $5 \%$ $\mathrm{CO}_{2}$ for $60 \mathrm{~h}$. And then condensed by high-speed centrifugation $\left(100,000 \mathrm{x} \mathrm{g}\right.$ at $4^{\circ} \mathrm{C}$ for $\left.2.5 \mathrm{~h}\right)$. Protein concentrations were confirmed using bicinchoninic acid (BCA) assays and the inactivated PEDV was diluted to a concentration of up to $100 \mu \mathrm{g} / 100 \mu \mathrm{l}$ in LB broth. In the present study, the PEDV was placed in a $6-\mathrm{cm}$ plate and illuminated for $12 \mathrm{~h}$ using a UV lamp. A total of 24, 0-day-old specific pathogen free (SPF) Duroc Landrace Yorkshire (DLY) piglets (12 males; 12 females; mean body weight $\sim 1.5 \mathrm{~kg}$ ) were provided by the Institute of Veterinary Research, Jiangsu Academy of Agricultural Sciences. Colostrum was not provided to the piglets. The piglets were kept in individual cages and food and water were given ad libitum under the same standard conditions at $12 \mathrm{~h}$ light/dark cycles. The temperature of the cages was $30^{\circ} \mathrm{C}$ in the first week and kept $26^{\circ} \mathrm{C}$ in the subsequent weeks of the experimental period. The relative humidity of the atmosphere was maintained at $70 \%$.

Antibodies. Goat anti-pig IgA (1:100; cat. no. ab112639) and rabbit anti-pig CD3 (SP7) (1:100; cat. no. ab16669) monoclonal antibodies were purchased from Abcam. The streptavidin-biotin complex (SABC) kit (Wuhan Boster Biological Technology, Ltd), including biotinylated goat anti-rabbit IgG (cat. no. sa1022), biotinylated rabbit anti-goat IgG antibodies (cat. no. sa1023) and horseradish peroxidase (HRP)-labeled SABC, was purchased from Boster Biological Technology. The 3,3-diaminobenzidine (DAB) HRP Color Development kit (cat. no. ar1022) was also purchased from Boster Biological Technology.
Experimental design and collection of samples. A total of 24 SPF DLY piglets, born on the same day, were raised in individual cages with high sanitary conditions. They were weighed and randomly assigned to four groups, each group containing 6 piglets. All piglets were first immunized at 5 days of age and were given a booster immunization at 12 days of age. The groups established were as follows: i) Control group, oral immunization with $1,100 \mu 1$ phosphate-buffered saline (PBS); ii) inactivated PEDV group, oral immunization with $100 \mu \mathrm{l}$ inactivated PEDV (100 $\mu \mathrm{g} /$ dose) combined with $1 \mathrm{ml}$ PBS; iii) oral-PB group, oral immunization with $100 \mu$ inactivated PEDV (100 $\mu \mathrm{g} /$ dose) combined with $1 \times 10^{9}$ colony-forming units (CFU) B. subtilis; and iv) nasal-PB group, nasal immunization with $100 \mu \mathrm{l}$ inactivated PEDV (100 $\mu \mathrm{g} /$ dose $)$ combined with $1 \times 10^{9} \mathrm{CFU}$ of $B$. subtilis.

The piglets were fasted for $3 \mathrm{~h}$ before each sample collection. Collection of each sample was performed between 10:00 and 11:00 a.m. before feeding. For the detection of IgG antibody levels in the serum, $2 \mathrm{ml}$ blood sample was collected from the precaval vein, once a week on days $0,7,14,21$ and 28 after the initial immunization. Serum was collected after centrifugation at $13,000 \mathrm{x} \mathrm{g}$ for $20 \mathrm{~min}$ at $4^{\circ} \mathrm{C}$ and stored at $-70^{\circ} \mathrm{C}$. Saliva as well as nasal and anal secretions were also collected on days $0,7,14,21$ and 28 after the initial immunization using cotton swabs. Piglets were fasted for $3 \mathrm{~h}$ before saliva collection. Saliva was collected using a cotton swab that was bitten by the piglets three times. Nasal secretions were collected using cotton swabs that were inserted $1.5 \mathrm{~cm}$ into the nose. Anal samples were collected using cotton swabs that were inserted $4 \mathrm{~cm}$ into the rectum. Subsequently, the collected samples were rapidly diluted in $800 \mu \mathrm{l} \mathrm{PBS}$, vortexed for $30 \mathrm{sec}$, centrifuged at $3,000 \mathrm{x} \mathrm{g}$ at $4^{\circ} \mathrm{C}$ for $10 \mathrm{~min}$ and stored at $-70^{\circ} \mathrm{C}$ for ELISA detection. Piglets were euthanized by the intravenous injection of sodium pentobarbital $(100 \mathrm{mg} / \mathrm{kg})$ at 33 days of age. The pigs were confirmed dead when the corneal reflex disappeared, breathing stopped and the heart stopped beating. Fresh intestines were rinsed using $1 \mathrm{ml}$ DMEM (Wisent Biotechnology) prior to analysis in the plaque reduction neutralization test (PRNT). A portion of small intestine tissue was fixed in Bouin's fluid (picric acid, 4\% paraformaldehyde, glacial acetic acid) at room temperature for $24 \mathrm{~h}$ for staining and another small intestine portion was collected and stored at $-70^{\circ} \mathrm{C}$ for cytokine detection. All animal experiments were approved by the Ethics Committee of Animal Experiments of the College of Veterinary Medicine, Nanjing Agricultural University. All animal care and use were conducted in strict accordance with the Animal Research Committee guidelines of the College of Veterinary Medicine, Nanjing Agricultural University.

ELISA for PEDV-specific SIgA in the local mucosa and IgG in the serum. The protein concentration of serum and the supernatant of mucosal secretions were measured using a BCA protein assay kit (Thermo Fisher Scientific, Inc.). The PEDV-specific antibody levels were detected using ELISA. Briefly, ELISA plates were coated in PEDV, $2 \mu \mathrm{g}$ purified $\mathrm{PEDV} /$ well, at $4^{\circ} \mathrm{C}$ overnight. The plates were washed with PBS containing $0.05 \%$ Tween-20 (PBS-T) to remove the virus. After virus removal, plates were blocked for $2 \mathrm{~h}$ at $37^{\circ} \mathrm{C}$ with 3\% BSA (Sigma-Aldrich; Merck KGaA) dissolved in PBS. Subsequently, 1:100 dilutions of serum samples or 1:2 dilutions 
of lavage fluid from small intestines, were added to the plates and incubated at $37^{\circ} \mathrm{C}$ for $1.5 \mathrm{~h}$. The plates were washed with PBST and then $100 \mu \mathrm{l}$ of HRP-conjugated goat anti-pig IgA antibody (1:2,000; cat. no. ab112746; Abcam) was added and the plates were incubated at $37^{\circ} \mathrm{C}$ for $1 \mathrm{~h}$. Plates were washed 5 times and incubated with 3,3'- and 5,5'-tetramethylbenzidine (TMB) at $37^{\circ} \mathrm{C}$ for $15 \mathrm{~min}$. The reaction was then stopped with $2 \mathrm{M}$ sulfuric acid and the absorbance was read at $450 \mathrm{~nm}$ using a microplate reader (Tecan Group, Ltd.).

PRNT for the PEDV neutralizing antibody. PRNT was performed as described in a previous study (8). Fresh intestinal samples were rinsed three times with $1 \mathrm{ml}$ DMEM. DMEM containing intestine washing liquid was centrifuged at $14,600 \mathrm{x} \mathrm{g}$ at $4^{\circ} \mathrm{C}$ for $15 \mathrm{~min}$ to remove the feces. The intestine washing liquid was then serially diluted two-fold in DMEM. PEDV PRNT was performed in monolayers of Vero cells $\left(1.0 \times 10^{6}\right.$ cells $\left./ \mathrm{ml}\right)$ in DMEM containing $10 \%$ FBS in 12-well plates. In brief, $\log$ dilutions (1:16, 1:32 and 1:64) of intestinal washing liquid $(450 \mu \mathrm{l})$ were incubated with $50 \mu \mathrm{l} 1 \times 10^{3}$ plaque-forming units of PEDV at $37^{\circ} \mathrm{C}$ for $1 \mathrm{~h}$. The $500 \mu \mathrm{l}$ virus/intestinal sample mixture was then transferred onto Vero cell monolayers and incubated at $37^{\circ} \mathrm{C}$ for $1 \mathrm{~h}$. The cell monolayers were washed with DMEM and overlaid with $0.9 \%$ low-melting agarose at $37^{\circ} \mathrm{C}$ in $5 \% \mathrm{CO}_{2}$ for $72 \mathrm{~h}$. Plaques were visualized by staining the monolayer with $0.5 \%$ crystal violet. Plaque images were acquired under ultraviolet radiation light in Tanon 5200 Automatic Chemiluminescence/Fluorescence Image Analysis system (Tanon Science and Technology Co., Ltd,).

Hematoxylin and eosin $(H \& E)$ staining for intestine intraepithelial lymphocytes (IELs) and Peyer's patches. Intestinal tissues were fixed in Bouin's fluid at room temperature for $24 \mathrm{~h}$ and then dehydrated through a serial alcohol gradient $(75 \%$ overnight, $85 \%$ for $1 \mathrm{~h}, 95 \%$ for $1 \mathrm{~h}$ and $100 \%$ for $2 \mathrm{~h}$ ), washed with xylene $(5 \mathrm{~min})$ at room temperature and finally embedded in paraffin. The embedded intestinal tissues were cut into 5- $\mu \mathrm{m}$ serial sections and placed on glass slides. Methods of revealing intraepithelial lymphocytes by H\&E staining have been previously reported (17). Before staining, paraffin sections were dewaxed in xylene at room temperature for $15 \mathrm{~min}$, rehydrated through decreasing concentrations of ethanol (100\% for $2 \mathrm{~min}$, 95\% for $1 \mathrm{~min}, 85 \%$ for $1 \mathrm{~min}$ and $75 \%$ for $1 \mathrm{~min}$ ) and rinsed in PBS for 2 min at room temperature. Following the hydration of paraffin sections through decreasing concentrations of ethanol, $\mathrm{H} \& \mathrm{E}$ staining was conducted using hematoxylin $(0.5 \%$ for $20 \mathrm{sec})$ and eosin $(0.5 \%$ for $5 \mathrm{sec})$ at room temperature. After staining, sections were dehydrated through increasing concentrations of ethanol (75\% for $1 \mathrm{~min}, 85 \%$ for $1 \mathrm{~min}, 95 \%$ for $1 \mathrm{~min}$, and $100 \%$ for $2 \mathrm{~min}$ ) and xylene (10 $\mathrm{min}$ ) at room temperature, and finally sealed with a coverslip. IELs were measured by counting $\geq 500$ nuclei (epithelial and lymphocyte) and the results expressed as IEL/100 epithelial cells (20). In the present study, 10 fields of view were randomly selected from each group and three intestinal villi were randomly selected per field. The numbers of IELs were counted in an area of 100 epithelial cells using a light microscope (CX23; Olympus Corporation; magnification, x40). The area of Peyer's patches was measured after H\&E staining. The area of Peyer's patches was measured using a light microscope (CX23; Olympus Corporation; magnification, x10) equipped with a digital camera (MD30; Guangzhou Micro-shot Technology Co., Ltd.) and image analysis software (Mshot Image Analysis System v1.0; Guangzhou Micro-shot Technology Co., Ltd.). The area was calculated based on a previous report (21). In the present study, 10 images were randomly selected from each group to measure the area of Peyer's patches (22).

Immunohistochemistry for IgA-secreting cells and $C D 3^{+}$ lymphocytes in the intestine. Preparation of paraffin sections, dewaxing and hydration were conducted as aforementioned. The endogenous peroxidase activity was neutralized using $3 \% \mathrm{H}_{2} \mathrm{O}_{2}$ at $37^{\circ} \mathrm{C}$ for $30 \mathrm{~min}$ and the sections were rinsed three times with PBS for $15 \mathrm{~min}$. Antigens were unmasked by microwaving $(800 \mathrm{~W})$ in citrate buffer (containing $2 \mathrm{mM}$ citric acid and $10 \mathrm{mM}$ trisodium citrate; $\mathrm{pH} \mathrm{6.0)} \mathrm{for} 15 \mathrm{~min}$. The sections were then treated with $5 \%$ BSA at $37^{\circ} \mathrm{C}$ for $1 \mathrm{~h}$ to block non-specific binding prior to incubation with rabbit anti-pig CD3 (1:100; cat. no. ab16669; Abcam) or goat anti-pig IgA (1:100; cat. no. ab112639; Abcam) overnight at $4^{\circ} \mathrm{C}$. The paraffin sections were rinsed three times with PBS for $15 \mathrm{~min}$ and then incubated with biotinylated goat anti-rabbit IgG or rabbit anti-goat $\operatorname{IgG}$ at $37^{\circ} \mathrm{C}$ for $1 \mathrm{~h}$. The paraffin sections were then rinsed three times with PBS and incubated with HRP labeled $\mathrm{SABC}$ at $37^{\circ} \mathrm{C}$. After $1 \mathrm{~h}$, the paraffin sections were rinsed three times with PBS and stained with DAB at room temperature for $2 \mathrm{~min}$. Cells were counterstained with $0.5 \%$ hematoxylin for $20 \mathrm{sec}$ at room temperature. After staining, sections were dehydrated through increasing concentrations of ethanol (75\% for $1 \mathrm{~min}, 85 \%$ for $1 \mathrm{~min}, 95 \%$ for $1 \mathrm{~min}$ and $100 \%$ for $2 \mathrm{~min}$ ) and xylene $(10 \mathrm{~min})$ at room temperature, and finally sealed with a coverslip. All incubations were performed in a humidified chamber. Control staining was carried out simultaneously, in which the primary antibody was replaced with PBS. No specific staining was found for the control staining (without antibody). Sections were sealed with glass coverslips. Optical density of $\mathrm{CD}^{+} \mathrm{T}$ cells was measured as previously described (23). The regions containing SIgA-secreting cells were counted using an optical microscope (24). A total of 20 images were randomly selected from each group and SIgA-secreting cells were counted in the same size field of view using the same multiple light microscope (CX23; Olympus Corporation; magnification, x40).

ELISA for interleukin (IL)-6 expression level in the intestine. Small intestine tissue was placed in 1.5-ml cryogenic vials containing $500 \mu \mathrm{l}$ PBS and triturated using a Tissuelyser-24L multi-sample tissue grinder (Shanghai Jingxin Industrial Development Co., Ltd). The supernatant of the homogenate was collected after a $12,000 \mathrm{x}$ g centrifugation for $10 \mathrm{~min}$ at $4^{\circ} \mathrm{C}$ for the detection of IL- 6 . The protein concentration of the supernatant was measured using a BCA protein assay kit (Thermo Fisher Scientific, Inc.). After a 10-fold dilution, the expression levels of IL-6 were measured using an ELISA kit (cat. no. ab100755; Abcam) according to the manufacturer's instructions. A total of $100 \mu 1$ of each standard and sample was added to the antibody-conjugated wells. The wells were covered and incubated overnight at $4^{\circ} \mathrm{C}$ with gentle shaking. The solution was discarded and washed 4 times with $300 \mu \mathrm{l}$ 
of $1 \mathrm{X}$ Wash Solution using a multi-channel pipette. After the final wash, the solution was removed by aspiration or decantation. A total of $100 \mu 1$ of biotinylated IL-6 antibody (cat. no. ab100755; Abcam) was added to each well. The samples were incubated for $1 \mathrm{~h}$ at room temperature with gentle shaking and then the solution was discarded. The washing step was repeated as previously performed. A total of $100 \mu \mathrm{l}$ of $1 \mathrm{X}$ HRP-Streptavidin solution was added to each well and incubated for $45 \mathrm{~min}$ at room temperature with gentle shaking. The solution was discarded and $100 \mu 1$ TMB One-Step Substrate Reagent was added to each well. This was incubated for $30 \mathrm{~min}$ at room temperature in the dark with gentle shaking. A total of $50 \mu \mathrm{l}$ Stop Solution was added to each well. Data were immediately acquired using an automated ELISA plate reader at $450 \mathrm{~nm}$.

ELISA for interferon (IFN)- $\gamma$ expression level in the intestine. The steps and methods of sample processing were consistent with those for IL-6. After a 5-fold dilution, the expression levels of IFN- $\gamma$ were measured using an ELISA kit (cat. no. ab113353; Abcam) according to the manufacturer's instructions. In brief, $50 \mu \mathrm{l}$ of each standard was added with the sample to the antibody-conjugated wells. The wells were covered and incubated overnight at $4{ }^{\circ} \mathrm{C}$ with gentle shaking. The solution was discarded and washed 5 times with $1 \mathrm{X}$ Wash Solution. After the final wash, the solution was removed by decantation. A total of $100 \mu \mathrm{l}$ of $1 \mathrm{X}$ biotinylated IFN- $\gamma$ antibody (cat. no. ab113353; Abcam) was added to each well. The samples were incubated for $1 \mathrm{~h}$ at room temperature with gentle shaking and then the solution was discarded. The washing step was repeated as previously performed. A total of $100 \mu \mathrm{l}$ of 1X HRP-Streptavidin solution was added to each well and incubated for $45 \mathrm{~min}$ at $37^{\circ} \mathrm{C}$. The solution was discarded and $100 \mu 1$ TMB One-Step Substrate Reagent was added to each well. The samples were then incubated for $10 \mathrm{~min}$ at $37^{\circ} \mathrm{C}$ in the dark. A total of $50 \mu \mathrm{l}$ Stop Solution was subsequently added to each well. Data were immediately acquired using an automated ELISA plate reader at $450 \mathrm{~nm}$.

Reverse transcription-quantitative PCR (RT-qPCR) for IFN- $\gamma$ in the intestine. Small intestine tissue was placed in $1.5-\mathrm{ml}$ cryogenic vials containing $1 \mathrm{ml}$ RNAiso Plus (Takara Bio, Inc.) and triturated in a Tissuelyser-24. The supernatant of these homogenates was collected after centrifugation at $12,000 \mathrm{xg}$ for $15 \mathrm{~min}$ at $4^{\circ} \mathrm{C}$. Total RNA was extracted using RNAiso Plus reagent (Takara Bio, Inc.) according to the manufacturer's instructions. RNA concentration and purity were measured using a NanoDrop 2000 (Thermo Fisher Scientific, Inc.). cDNA synthesis was performed by incubating $15 \mu \mathrm{l}$ double distilled water (DDW), $4 \mu 1$ 5X PrimeScript RT Master mix (Shanghai Yeasen Biotechnology Co., Ltd) and $1 \mu 1$ template RNA (diluted to $500 \mathrm{ng} / \mu \mathrm{l}$ ) at $37^{\circ} \mathrm{C}$ for $15 \mathrm{~min}$ and $85^{\circ} \mathrm{C}$ for $15 \mathrm{sec}$. The reference gene used was GAPDH. Primers for IFN- $\gamma$ were synthesized by GenScript. The primers used were as follows: IFN- $\gamma$, forward 5'-GCTCTGGGAAACTGAATGAC-3' and reverse 5'-TCTCTGGCCTTGGAACATAG-3'; and GAPDH, forward 5'-CTTCACGACCATGGAGAAGG-3' and reverse 5'-CCAAGCAGTTGGTGGTACAG. qPCR was performed on a real-time PCR machine (Hangzhou Bioer Co., Ltd.) in a $20 \mu \mathrm{l}$ reaction volume containing $10 \mu 12 X$ SYBRGreen Master Mix
(Takara Bio, Inc.), $0.4 \mu \mathrm{l}$ each primer, $2 \mu \mathrm{l}$ template cDNA and 7.2 $\mu \mathrm{l}$ DDW. The thermocycling conditions used for the PCR were as follows: Initial denaturation $95^{\circ} \mathrm{C}$ for $5 \mathrm{sec}, 40$ cycles of $95^{\circ} \mathrm{C}$ for $30 \mathrm{sec}$ and $60^{\circ} \mathrm{C}$ for $34 \mathrm{sec}$. The relative expression levels were calculated using the $2^{-\Delta \Delta \mathrm{Cq}}$ method (25).

Statistical analysis. GraphPad Prism V6.0 (GraphPad Software, Inc.) was used to perform the statistical analyses. One-way ANOVAs and repeated-measures ANOVAs were used to analyze the significance of the differences between means. Bonferroni's correction was used to analyze PEDV-specific titer datasets, while Tukey's multiple comparison tests were used to analyze the other datasets. Values are shown as the mean \pm SD. $\mathrm{P}<0.05$ was considered to indicate a statistically significant difference and $\mathrm{P}<0.01$, a highly significant difference.

\section{Results}

PEDV-specific SIgA and IgG titers. After receiving the first immunization, PEDV-specific mucosal SIgA titers exhibited an upward trend at days 7-14 for all groups (Fig. 1A-C). Following nasal immunization with inactivated PEDV combined with B. subtilis, SIgA titers significantly increased on day 7 after the initial immunization compared with oral immunization with inactivated PEDV. The titers of PEDV-specific SIgA peaked in saliva and nasal secretions on day 14, 7 days after the booster immunization, especially following nasal immunization with inactivated PEDV combined with $B$. subtilis. Although PEDV-specific SIgA titers declined after day 14 in all treatments, nasal immunization exhibited higher titers than the other treatments over the 28-day period. The SIgA level in feces did not reach a maximum on day 14 after the initial immunization, as with the nasal and saliva SIgA levels, as the immunization was administered orally and nasally. Therefore, the increased fecal SIgA level did not persist for as long as the levels in the saliva and nasal secretions. A variation in the IgG titers was detected in the serum (Fig. 1D). IgG titers were maintained at high levels after nasal immunization with inactivated PEDV combined with $B$. subtilis throughout the collection period after the initial immunization. No significant differences were detected in SIgA titers of the negative control group during the experiment. A timeline of the immunization program and sampling times is presented in Fig. 1E.

PEDV PRNT. The PEDV neutralization antibody level was evaluated using PRNTs. The number of plaques was proportional to the level of neutralizing antibodies. At the same dilution ratio, the plaque number decreased $(\mathrm{P}<0.01)$ after oral immunization with inactivated PEDV combined with B. subtilis, compared with inactivated PEDV alone (Fig. 2). After nasal immunization with inactivated PEDV combined with $B$. subtilis, the number of plaques decreased compared with oral immunization $(\mathrm{P}<0.05)$. With the exception of the control group, the number of plaques increased gradually according to the dilution ratio.

IEL numbers and determination of Peyer's patch areas. Fig. 3A indicated that the IELs were located between epithelial cells and at the basal epithelia. Changes in the number of IELs 

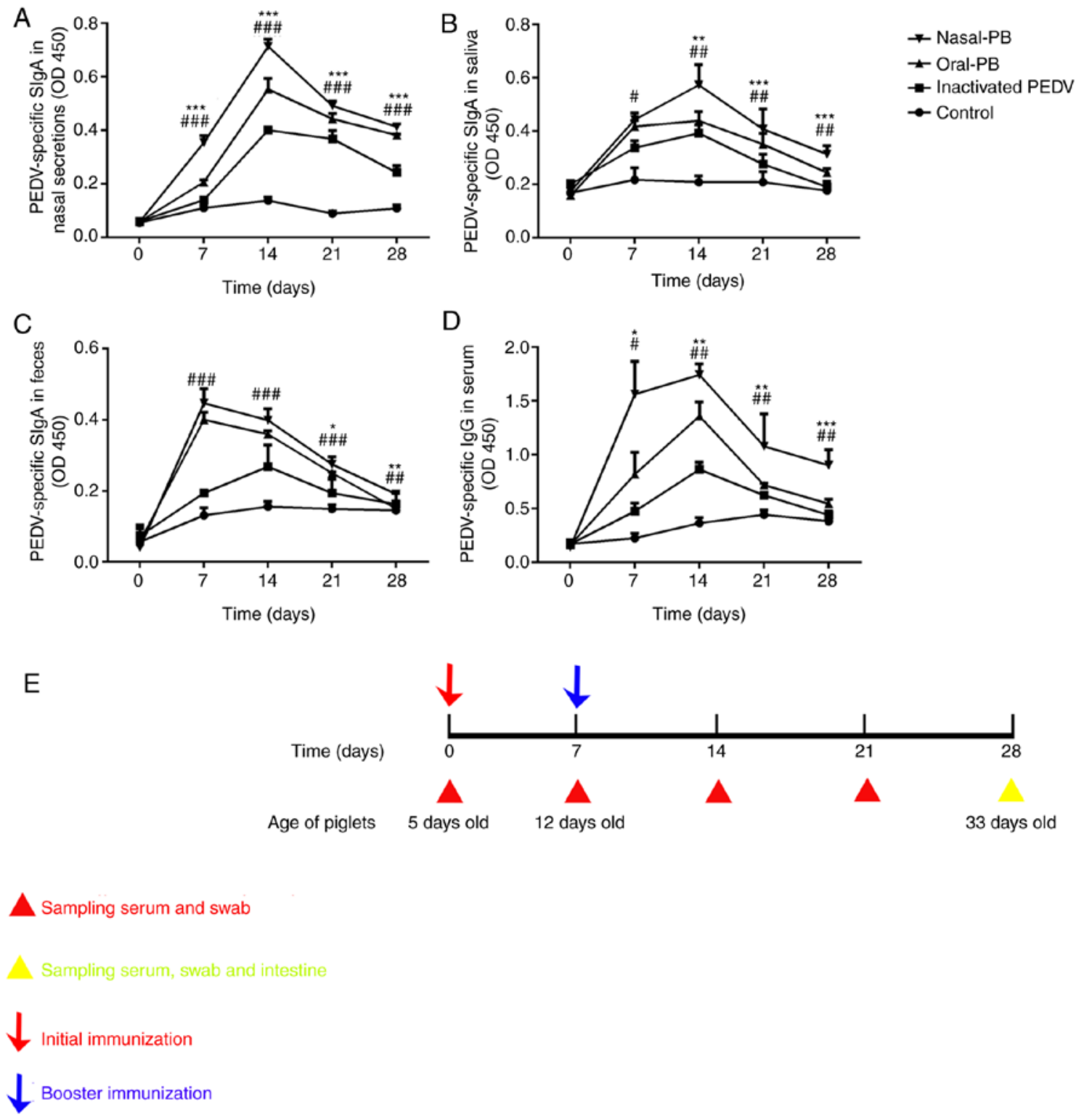

Figure 1. Changes in PEDV-specific SIgA titers in the local mucosa and IgG titers in the serum. ELISA detection of PEDV-specific SIgA titers in (A) nasal secretions, (B) saliva and (C) feces. (D) ELISA detection of PEDV-specific IgG titers in serum. (E) The immunization program and sampling times. Data were acquired using an automated ELISA plate reader at $450 \mathrm{~nm}$. Data are presented as the mean $\pm \mathrm{SD}$. ${ }^{*} \mathrm{P}<0.05,{ }^{* *} \mathrm{P}<0.01,{ }^{* * * *} \mathrm{P}<0.001$, oral-PB group vs. nasal-PB group; ${ }^{\#} \mathrm{P}<0.05 ;{ }^{\# \#} \mathrm{P}<0.01,{ }^{\# \# \#} \mathrm{P}<0.001$, oral-PB group vs. inactivated PEDV group. Nasal-PB, nasal immunization with inactivated PEDV combined with $B$. subtilis; OD, optical density; oral-PB, oral immunization with inactivated PEDV combined with B. subtilis; PEDV, porcine epidemic diarrhea virus; SIgA, secretory immunoglobulin $\mathrm{A} ; \mathrm{IgG}$, immunoglobulin $\mathrm{G}$.

are presented in Fig. 3B, and the number of IELs was demonstrated to increase significantly after nasal immunization with inactivated PEDV combined with $B$. subtilis compared with oral immunization $(\mathrm{P}<0.05)$. No significant difference was identified after oral immunization with inactivated PEDV combined with $B$. subtilis compared with inactivated PEDV alone.

Peyer's patches are important inductive sites for the initiation of the adaptive immune response and function to maximize the immunological barrier of the host (26). The size of Peyer's patches serves an important role in their development $(27,28)$. The Peyer's patches were located in the mucosal basement of the small intestine (Fig. 3C). The change in the area of Peyer's patches is shown in Fig. 3. The area of Peyer's patches increased after oral immunization with inactivated PEDV combined with $B$. subtilis compared with inactivated PEDV alone $(\mathrm{P}<0.05)$. A significant increase was also identified after nasal immunization with inactivated PEDV combined with B. subtilis when compared with oral immunization $(\mathrm{P}<0.01)$.

IgA-secreting cell numbers. The majority of IgA-secreting cells were located in the submucosa of the intestine (Fig. 4A). The change in the number of IgA-secreting cells is presented in Fig. 4B. The number of IgA-secreting cells in the intestine increased following oral immunization with inactivated PEDV combined with $B$. subtilis compared with inactivated PEDV alone $(\mathrm{P}<0.05)$. A significant increase was observed following nasal immunization with inactivated PEDV combined with B. subtilis compared with the oral immunization group $(\mathrm{P}<0.05)$. 
A

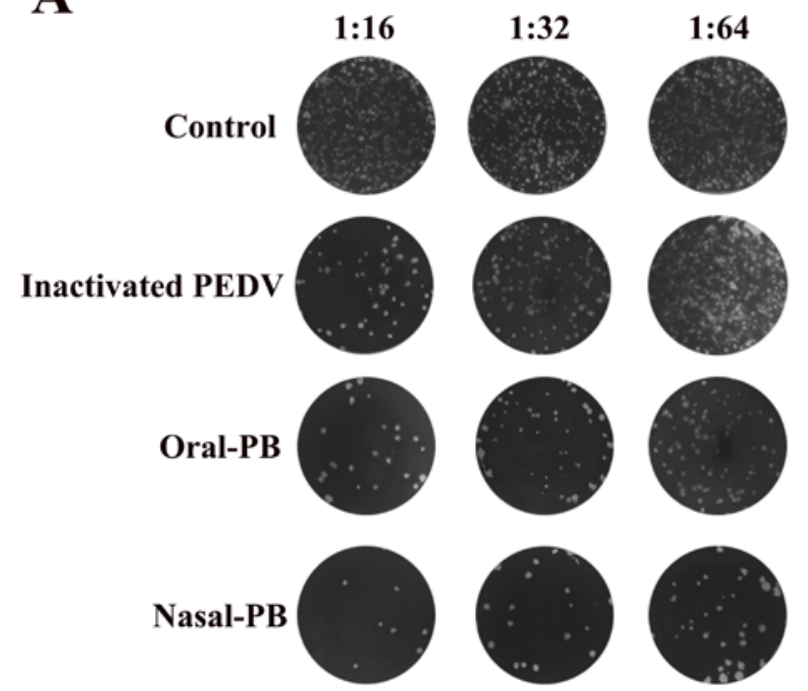

B

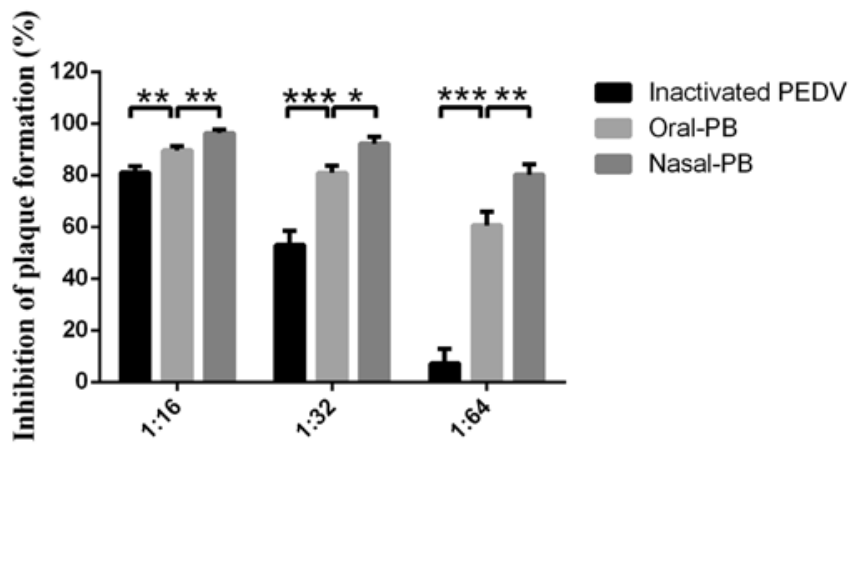

Figure 2. Changes in PEDV neutralizing antibody levels in the intestine. PEDV plaque reduction neutralization tests were performed in monolayers of Vero cells. (A) Images of plaques formed when the washing liquid was diluted at ratios of 1:16, 1:32 and 1:64. (B) Quantification of the inhibition of plaque formation at a variety of concentrations of intestinal samples. Data were obtained using the ratio of the number of plaques to the number in the control group. Data are presented as the mean $\pm \mathrm{SD}$. ${ }^{*} \mathrm{P}<0.05,{ }^{* *} \mathrm{P}<0.01,{ }^{* * *} \mathrm{P}<0.001$. Nasal-PB, nasal immunization with inactivated $\mathrm{PEDV}$ combined with $B$. subtilis; oral-PB, oral immunization with inactivated PEDV combined with $B$. subtilis; PEDV, porcine epidemic diarrhea virus.

Assessment of $\mathrm{CD}^{+}$T-cell numbers. The mucosal immune system generates immune responses via immune cells that reside in mucosal compartments (29). $\mathrm{CD}^{+} \mathrm{T}$ cells residing in the mucosa fulfill surveillance functions and are associated with the regulation of immune responses to pathogens (30). Therefore, $\mathrm{CD}^{+} \mathrm{T}$ cells in the intestines serve an important role in the adaptive mucosal immune response (31). $\mathrm{CD}^{+}$ $\mathrm{T}$ cells were identified in the lamina propria of villi in the intestine (Fig. 5A). CD3 ${ }^{+} \mathrm{T}$ cells were observed to be round in shape. The change in the number of $\mathrm{CD}^{+} \mathrm{T}$ cells was determined by calculating the optical density. After oral immunization with inactivated PEDV combined with $B$. subtilis (Fig. 5B), the $\mathrm{CD}^{+}$T-cell numbers in the intestine increased significantly compared with inactivated PEDV alone $(\mathrm{P}<0.05)$. Additionally, after nasal immunization, the number of $\mathrm{CD}^{+}$ $\mathrm{T}$ cells increased significantly $(\mathrm{P}<0.05)$ compared with oral immunization.

Estimation of IL-6 and IFN- $\gamma$ expression levels. After oral immunization with inactivated PEDV combined with $B$. subtilis, the expression levels of IL-6 in the intestine increased compared with inactivated PEDV alone $(\mathrm{P}<0.01)$. After nasal immunization, the expression levels of IL- 6 further increased significantly compared with oral immunization $(\mathrm{P}<0.05$; Fig. 6A).

To assess the cellular immunity levels in the intestine, intestinal IFN- $\gamma$ level was detected using RT-qPCR and ELISAs. After nasal immunization with inactivated PEDV combined with B. subtilis, the expression levels of IFN- $\gamma$ in the intestine were found to increase significantly compared with oral immunization $(\mathrm{P}<0.05)$. There was no difference in IFN- $\gamma$ protein levels although there was an increase in the mRNA levels $(\mathrm{P}<0.05)$, when comparing the oral immunization inactivated PEDV combined with $B$. subtilis to inactivated PEDV alone (Fig. 6B and C).

\section{Discussion}

The prevalence of PEDV infection worldwide is closely associated with the limited protection of conventional vaccines administered via intramuscular injection or orally (32). Therefore, an effective vaccine delivery strategy for preventing this disease remains to be developed. Nasal vaccination in pigs has made progress in controlling the outbreak of mucosal viral infections, including Rotavirus (33), Pseudorabies virus (34) and porcine reproductive and respiratory syndrome virus (35). Nasal vaccinations may induce superior immune responses in the nasal, intestinal and reproductive mucosa of pigs. Therefore, nasal administration with inactivated PEDV may be a promising strategy that can be used for inducing the immune response in the intestinal mucosa. In the present study, nasal immunization was found to induce the expression of intestinal IgA and systemic IgG to resist PEDV infection.

The selection of an appropriate immunopotentiator is important in aiding the design of a mucosal vaccine $(36,37)$. $B$. subtilis is a nonpathogenic gram-positive bacterium, a novel probiotic and a type of feed supplement. B. subtilis has its own unique resistance properties, such as high temperature resistance, and can survive under extreme conditions (38). Previous studies have also indicated that the intranasal administration of B. subtilis may increase the number of dendritic cells and IgA-secreting cells as well as enhance the immune response in the nasal mucosa of piglets $(39,40)$. Therefore, in the present study, B. subtilis was used as an immunopotentiator to elicit a stronger immune response after the vaccination of piglets with inactivated PEDV. In the present study, $B$. subtilis served only as an immunopotentiator to enhance the local mucosal immune response. Furthermore, a previous study has demonstrated the immune effects of $B$. subtilis after oral administration in pigs (41). Additionally, the number of healthy pigs was limited due to a recent outbreak of African swine fever in China. 
A

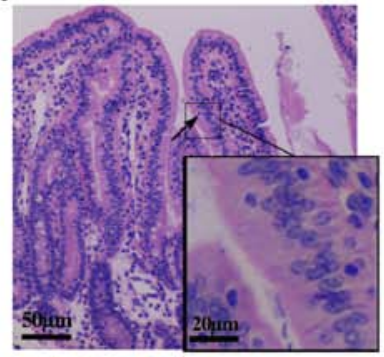

Oral-PB

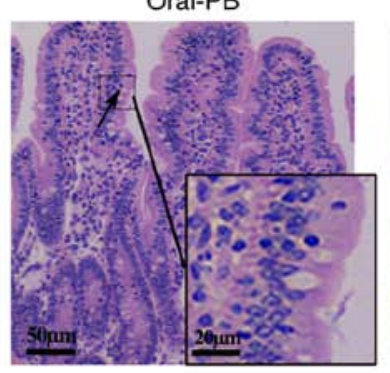

C
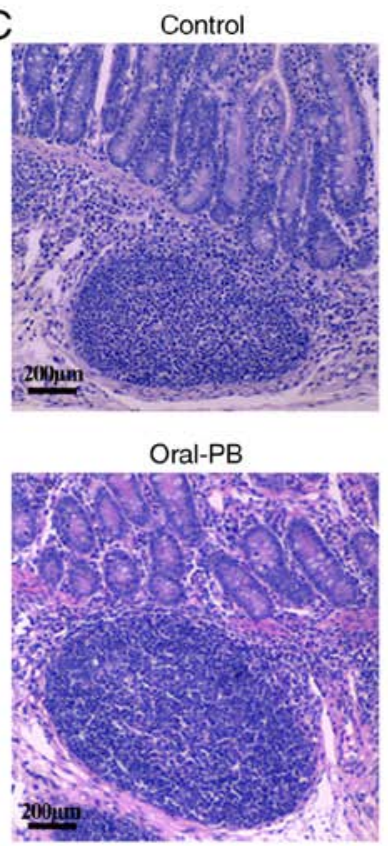

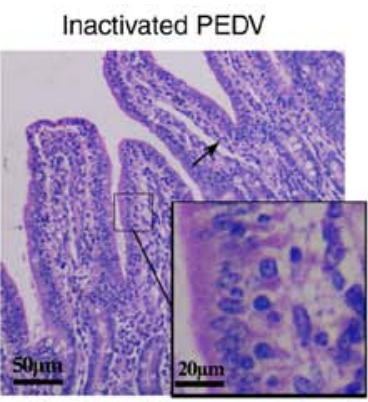

Nasal-PB

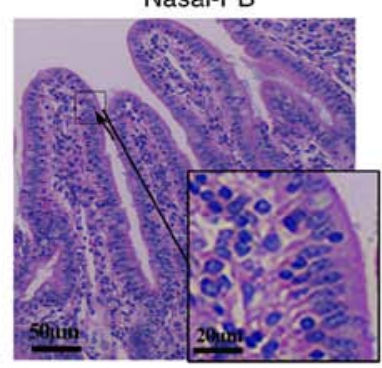

Inactivated PEDV

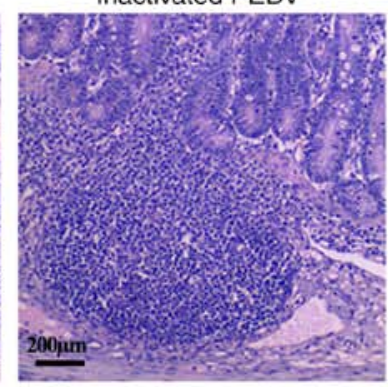

Nasal-PB

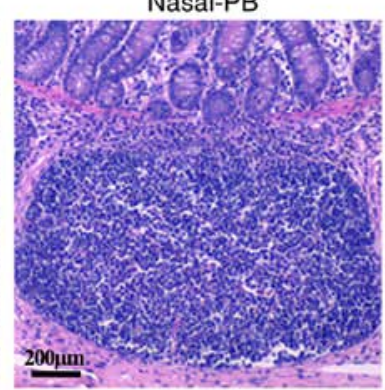

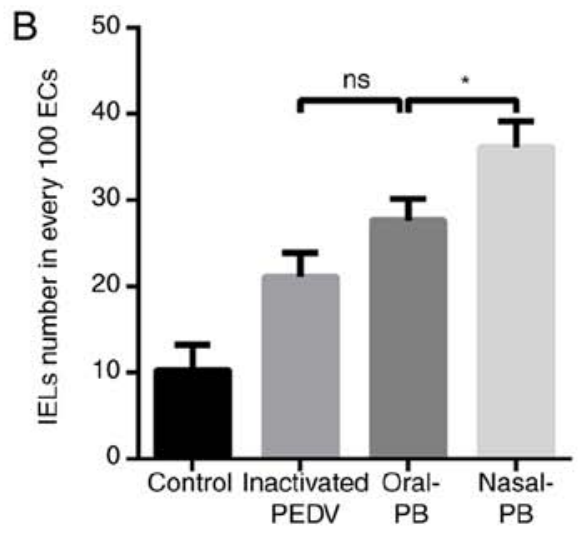

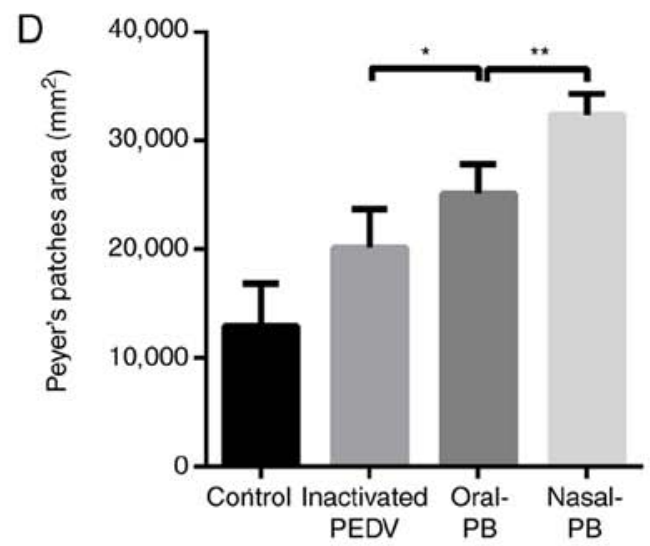

Figure 3. Changes of IEL numbers and Peyer's patch areas in the intestine. Fixed samples were embedded in paraffin and sectioned at 5- $\mu \mathrm{m}$ thickness. H\&E staining of the paraffin sections was performed. (A) H\&E staining for IELs. The arrows indicate the IELs. Scale bars, $20 \mu \mathrm{m}$ (inset) and $50 \mu \mathrm{m}$. (B) Changes in IEL numbers. (C) H\&E staining for Peyer's patches in the intestine. Peyer's patches are characterized by oval or round lymphoid follicles and were located in the submucosa layer of the intestine. Scale bars, $200 \mu \mathrm{m}$. (D) Changes in the area of Peyer's patches in the intestine. Data are presented as the mean \pm SD. ${ }^{*} \mathrm{P}<0.05,{ }^{* *} \mathrm{P}<0.01$. ns, no significant difference; SD, standard deviation; IEL, intestinal intraepithelial lymphocyte; EC, epithelial cell; H\&E, hematoxylin-eosin; nasal-PB, nasal immunization with inactivated PEDV combined with B. subtilis; oral-PB, oral immunization with inactivated PEDV combined with $B$. subtilis; PEDV, porcine epidemic diarrhea virus.

Therefore, a B. subtilis group was excluded from the present study.

The results of the study revealed that PEDV-specific SIgA exhibited higher levels in the saliva, feces and nasal secretions after nasal immunization with inactivated PEDV combined with B. subtilis when compared with oral immunization. Furthermore, increased PEDV-specific IgG titers were detected in the serum. The humoral immune responses are mediated by antibodies. SIgA is a complex of $\operatorname{Ig} \mathrm{A}$ that is produced by plasma cells and is the most abundant antibody in the intestinal mucosal surface (42). SIgA is capable of binding to pathogens and excluding their access to the intestine, and mediates pathogen clearance in the intestinal mucosal surface (43). In the present study, increased PEDV-specific SIgA titers in the intestine warranted further analysis. Based on the common mucosal immune theory, antigens administered via the nasal mucosal surface are taken up by antigen-presenting cells, including dendritic cells or microfold cells that migrate to the nasal-associated lymphoid tissue (44) and lead to the activation of antigen-specific T cells. Upon activation, antigen-specific 
A
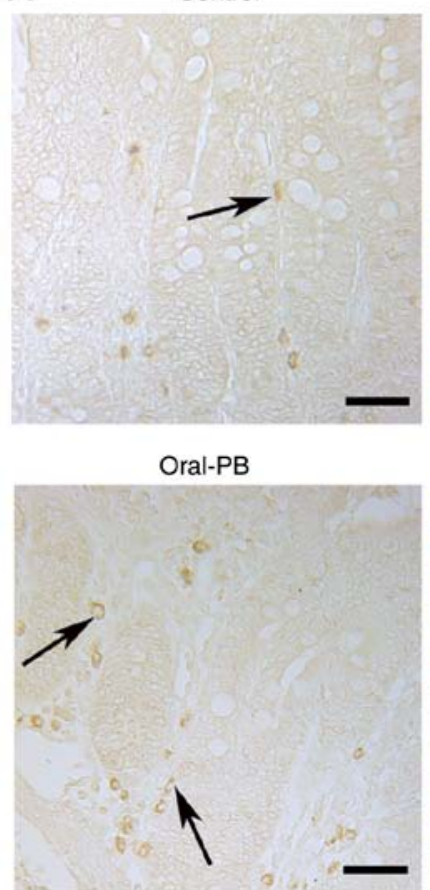

Inactivated PEDV

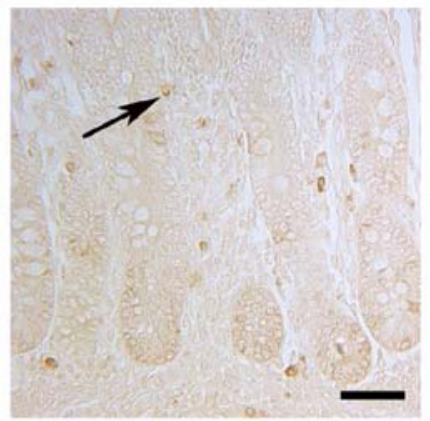

Nasal-PB

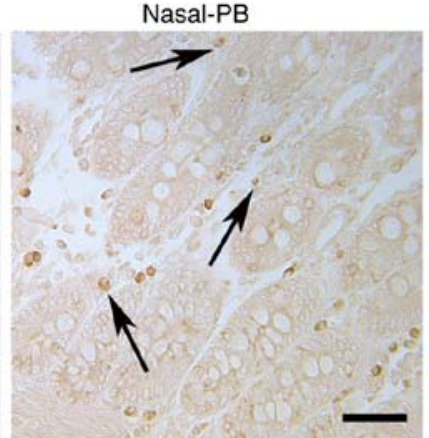

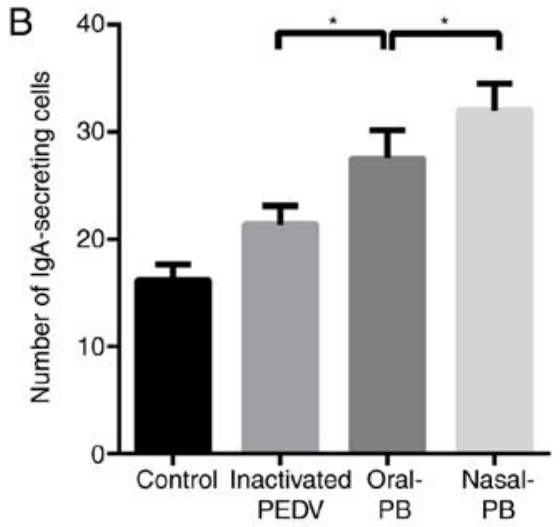

Figure 4. Changes in IgA-secreting cell numbers in the intestine. (A) IgA-secreting cells in the small intestine were detected using immunohistochemistry. The arrows show IgA secreting cells, with a round morphology. The nuclei are surrounded by a ring of yellow-brown cytoplasm in the lamina propria of intestinal villi. Scale bars, $50 \mu \mathrm{m}$. (B) Changes in the number of IgA-secreting cells. Data are presented as the mean \pm SD. *P<0.05 Ig, immunoglobulin; nasal-PB, nasal immunization with inactivated PEDV combined with $B$. subtilis; oral-PB, oral immunization with inactivated PEDV combined with $B$. subtilis; PEDV, porcine epidemic diarrhea virus.

A

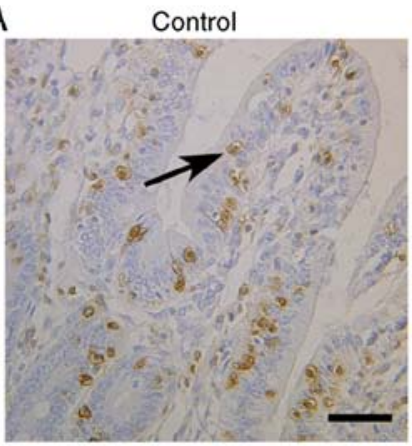

Oral-PB

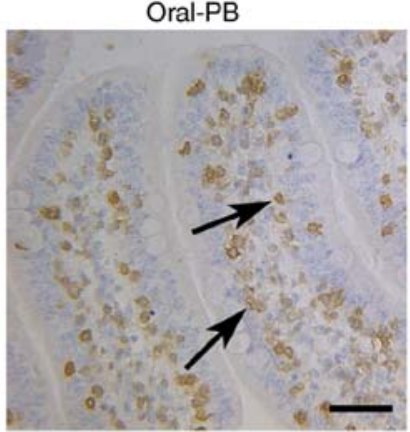

Inactivated PEDV

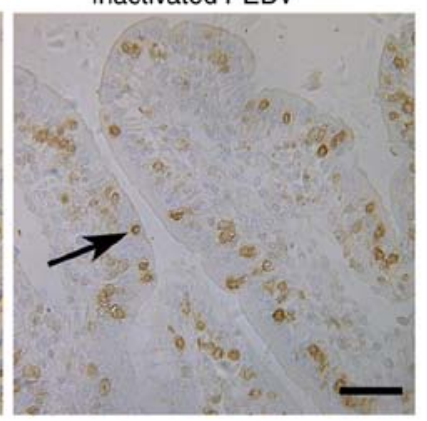

Nasal-PB

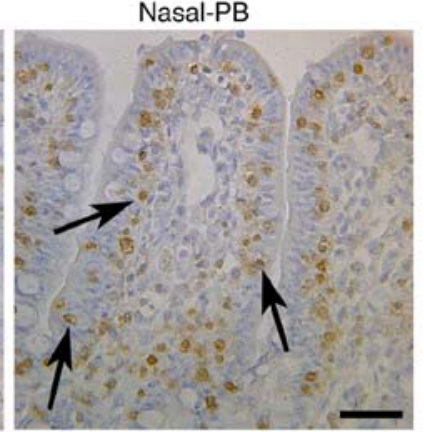

$\mathrm{B}$

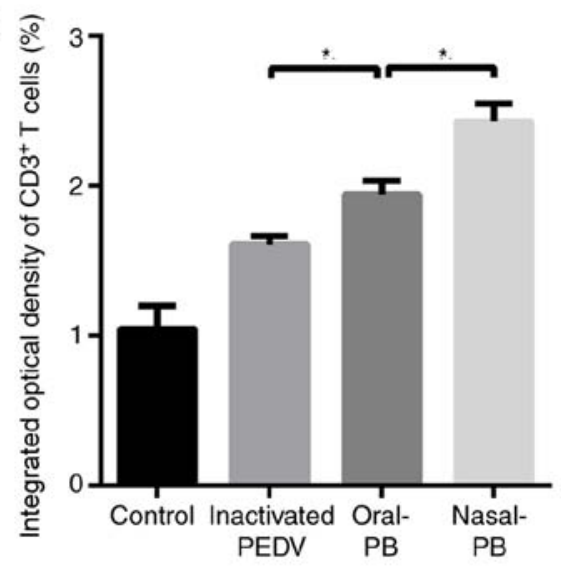

Figure 5. Changes in $\mathrm{CD}^{+} \mathrm{T}$-cell numbers in the intestine. (A) $\mathrm{CD}^{+} \mathrm{T}$ cells located in the villi of the intestine. The arrows show $\mathrm{CD} 3^{+} \mathrm{T}$ cells that were stained using anti-CD3-HRP and counterstained with hematoxylin. Scale bars, $50 \mu \mathrm{m}$. (B) Integrated optical density of CD3 ${ }^{+} \mathrm{T}$ cells in the intestine. Data are presented as the mean $\pm \mathrm{SD}$. $\mathrm{P}<0.05$. Nasal-PB, nasal immunization with inactivated PEDV combined with $B$. subtilis; oral-PB, oral immunization with inactivated PEDV combined with B. subtilis; PEDV, porcine epidemic diarrhea virus.

$\mathrm{T}$ cells proliferate and migrate to distant effector sites, including the intestinal mucosa (45). In the intestinal mucosa, activated T cells induce B cells to terminally differentiate into plasma cells and produce $\operatorname{Ig} \mathrm{A}$ in the presence of cytokines 

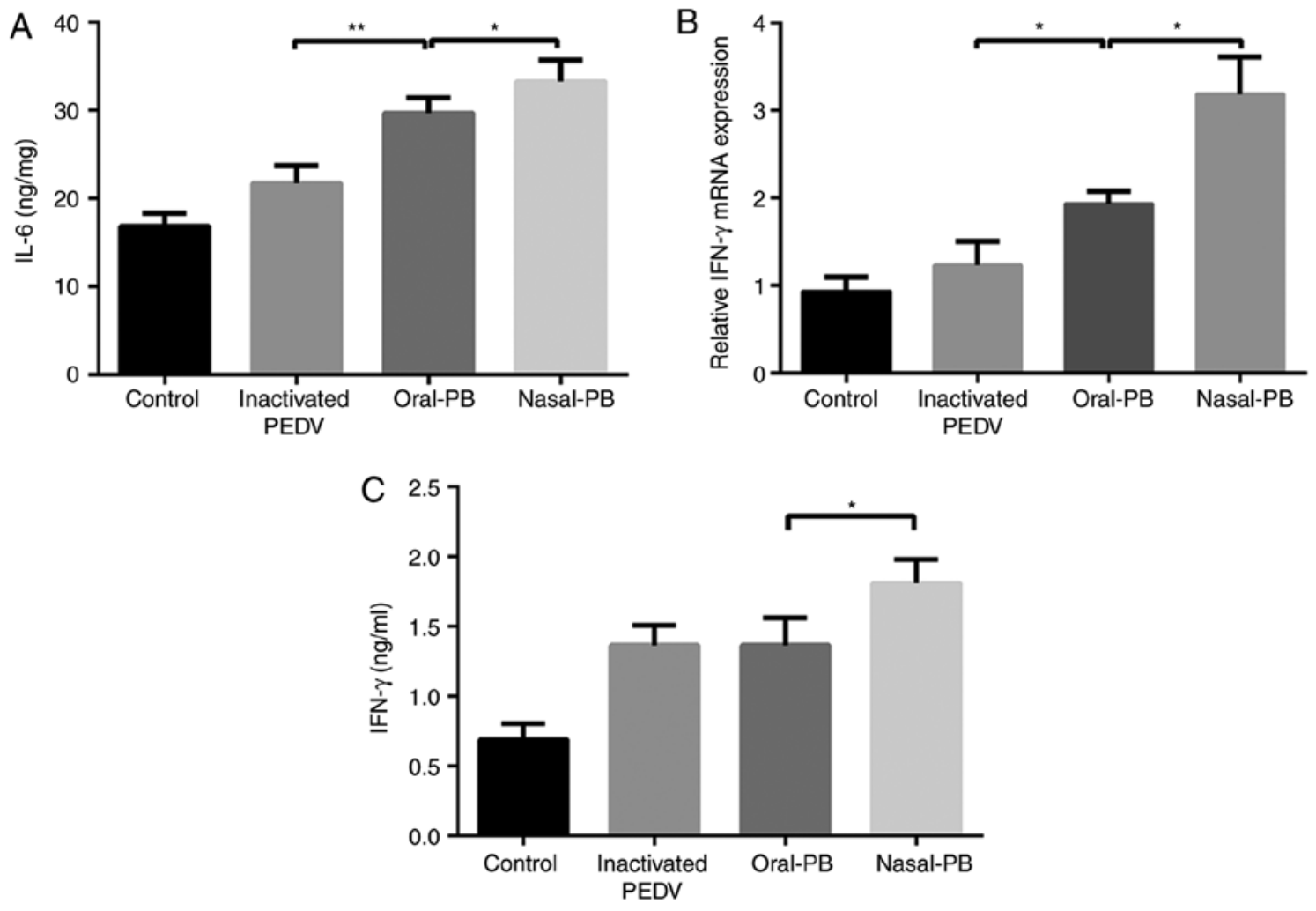

Figure 6. Changes in IL-6 and IFN- $\gamma$ expression levels in the intestine. (A) Changes in IL-6 expression levels in the intestine were detected using ELISAs. (B) Relative IFN- $\gamma$ mRNA expression levels were detected using reverse transcription-quantitative PCR. (C) The protein expression levels of IFN- $\gamma$ were detected using ELISAs. Data are presented as the mean $\pm \mathrm{SD}$. ${ }^{*} \mathrm{P}<0.05,{ }^{* *} \mathrm{P}<0.01$. IFN, interferon; IL, interleukin; nasal-PB, nasal immunization with inactivated PEDV combined with $B$. subtilis; oral-PB, oral immunization with inactivated PEDV combined with $B$. subtilis; PEDV, porcine epidemic diarrhea virus.

such as IL-6, which are produced by activated $\mathrm{T}$ cells in the intestine (46).

IEL numbers were observed to increase following the nasal immunization of piglets with inactivated PEDV combined with B. subtilis. Cellular immune responses are considered to be important in virus clearance (47). IELs are the first molecules likely to contact pathogens in the intestine (48). As a specialized T-cell population in the intestinal epithelium, IELs are considered to serve an important role in the regulation of mucosal immune responses (49). The present study indicated that oral infection of mice by rotavirus could expand and activate the IELs. Activated IELs induce the production of IFN- $\gamma$ to promote innate antiviral resistance (50). Therefore, increased IEL numbers may promote the generation of IFN- $\gamma$ to defend against PEDV directly in the intestine.

The results of the present study demonstrated that cytokine levels were elevated after nasal immunization of piglets with inactivated PEDV combined with $B$. subtilis. IL-6 and IFN- $\gamma$, which are secreted by immune cells, participate in regulating immune responses (51). Elevated IL- 6 and IFN- $\gamma$ expression levels in the intestine can enhance the overall levels of intestinal mucosal immunity (52). A previous study demonstrated that after the mucosal delivery of recombinant strains of Lactococcus lactis expressing IL-6, the production of IL-6 could stimulate the proliferation and differentiation of $\mathrm{B}$ cells (53), which explains the increases in IgA-secreting cells found in the intestine. Furthermore, the importance of IFN- $\gamma$ in mucosal immunity is derived in part from its robust antiviral activities. Previous studies have indicated that enhanced
IFN- $\gamma$ levels contribute to the clearance of the virus $(54,55)$. In the present study, increased IFN- $\gamma$ expression levels may induce the innate immune response of the intestinal epithelium, which may serve an important role in defending against PEDV infections.

It is worth noting that a number of vaccines can enter the gastrointestinal tract during nasal immunization $(56,57)$. A previous study developed a sheep model to detect the efficacy of nasal vaccine administration. The results indicated that the mucociliary action and involuntary swallowing directed a fraction of inhaled vaccines down the esophagus into the intestine, resulting in intestinal mucosal immunity (58). Therefore, nasal administration of a vaccine may exert a double immune effect.

Antiviral protection assays are the best method of evaluating immune responses. However, there are currently no suitable pigs due to an outbreak of African swine fever in China. This shortage of experiment materials was a limitation of the present study. Furthermore, the piglets were kept on PEDV-negative farms; therefore, the use of live PEDV was not permitted. Neutralizing antibodies indicate the body's ability to neutralize a virus, to a certain extent, and are a suitable alternative to antiviral challenge experiments $(8,17)$. Therefore, in the present study, the neutralization antibody plaque reduction test was performed instead of an assay of antiviral protection.

In conclusion, the present study revealed that nasal immunization could effectively improve humoral and cellular immune levels in the intestine. Furthermore, the administration of a vaccine nasally would be relatively easy, making nasal 
immunization a favorable route of mucosal immunization for the prevention of PEDV infections.

\section{Acknowledgements}

Not applicable.

\section{Funding}

The current study was supported by grants from the National Science Grant of China (grant nos. 31772777 and 31930109) and a project funded by the Priority Academic Program Development of Jiangsu Higher Education Institutions (PAPD).

\section{Availability of data and materials}

The datasets used and/or analyzed during the current study are available from the corresponding author on reasonable request.

\section{Authors' contributions}

EZ, JW, LH and QY conceived the study. EZ and QY participated in the design of the protocols for the study. EZ and JW performed the experiments. EZ, JW, YL, LH and YW analyzed the data. EZ wrote the manuscript. QY, EZ, JW and YL participated in the revision of the manuscript. All authors read and approved the final manuscript.

\section{Ethics approval and consent to participate}

All animal experiments were approved by the Ethics Committee of Animal Experiments of the College of Veterinary Medicine, Nanjing Agricultural University. All animal care and use were conducted in strict accordance with the Animal Research Committee guidelines of the College of Veterinary Medicine, Nanjing Agricultural University.

\section{Patient consent for publication}

Not applicable.

\section{Competing interests}

The authors declare that they have no competing interests.

\section{References}

1. Song D, Huang D, Peng Q, Huang T, Chen Y, Zhang T, Nie X, He H, Wang P, Liu Q and Tang Y: Molecular characterization and phylogenetic analysis of porcine epidemic diarrhea viruses associated with outbreaks of severe diarrhea in piglets in Jiangxi, China 2013. PLoS One 10: e0120310, 2015.

2. Song D and Park B: Porcine epidemic diarrhoea virus: A comprehensive review of molecular epidemiology, diagnosis, and vaccines. Virus Genes 44: 167-175, 2012.

3. Li W, van Kuppeveld FJM, He Q, Rottier PJM and Bosch BJ: Cellular entry of the porcine epidemic diarrhea virus. Virus Res 226: 117-127, 2016.

4. Hou X, Jiang X, Jiang Y, Tang L, Xu Y, Qiao X, Min L, Wen C, $\mathrm{Ma} \mathrm{G}$ and Li Y: Oral immunization against PEDV with recombinant lactobacillus casei expressing dendritic cell-targeting peptide fusing COE Protein of PEDV in Piglets. Viruses 10 E106, 2018.

5. Wang D, Fang L and Xiao S: Porcine epidemic diarrhea in China. Virus Res 226: 7-13, 2016.
6. Mantis NJ and Forbes SJ: Secretory IgA: Arresting microbial pathogens at epithelial borders. Immunol Invest 39: 383-406, 2010.

7. Poles J, Alvarez Y and Hioe CE: Induction of intestinal immunity by mucosal vaccines as a means of controlling HIV infection. AIDS Res Hum Retroviruses 30: 1027-1040, 2014.

8. Wang J, Huang L, Mou C, Zhang E, Wang Y, Cao Y and Yang Q: Mucosal immune responses induced by oral administration recombinant Bacillus subtilis expressing the $\mathrm{COE}$ antigen of PEDV in newborn piglets. Biosci Rep 39: BSR20182028, 2019.

9. Li Y, Wu Q, Huang L, Yuan C, Wang J and Yang Q: An alternative pathway of enteric PEDV dissemination from nasal cavity to intestinal mucosa in swine. Nat Commun 9: 3811, 2018.

10. Guy B: Evaluation of events occurring at mucosal surfaces: Techniques used to collect and analyze mucosal secretions and cells. Clin Diagn Lab Immunol 9: 753-762, 2002.

11. Kozlowski PA, Williams SB, Lynch RM, Flanigan TP, Patterson RR, Cu-Uvin S and Neutra MR: Differential induction of mucosal and systemic antibody responses in women after nasal, rectal, or vaginal immunization: Influence of the menstrual cycle. J Immunol 169: 566-574, 2002.

12. Staats HF, Montgomery SP and Palker TJ: Intranasal immunization is superior to vaginal, gastric, or rectal immunization for the induction of systemic and mucosal anti-HIV antibody responses. AIDS Res Hum Retroviruses 13: 945-952, 1997.

13. Lauring AS Jones JO and Andino R: Rationalizing the development of live attenuated virus vaccines. Nat Biotechnol 28: 573-579, 2010.

14. Azegami T, Yuki Y and Kiyono H: Challenges in mucosal vaccines for the control of infectious diseases. Int Immunol 26: 517-528, 2014.

15. Amuguni $\mathrm{H}$ and Tzipori S: Bacillus subtilis: A temperature resistant and needle free delivery system of immunogens. Hum Vaccin Immunother 8: 979-986, 2012.

16. Upadhaya SD, Kim SC, Valientes RA and Kim IH: The effect of bacillus-based feed additive on growth performance, nutrient digestibility, fecal gas emission, and pen cleanup characteristics of growing-finishing pigs. Asian-Australas J Anim Sci 28: 999-1005, 2015.

17. Mou C, Zhu L, Xing X, Lin J and Yang Q: Immune responses induced by recombinant bacillus subtilis expressing the spike protein of transmissible gastroenteritis virus in pigs. Antiviral Res 131: 74-84, 2016.

18. Mou C, Zhu L, Yang J, Xu W, Cheng X and Yang Q: Immune responses induced by recombinant bacillus subtilis expressing the hemagglutinin protein of H5N1 in chickens. Sci Rep 6: 38403, 2016.

19. Li Y, Wang G, Wang J, Man K and Yang QJV: Cell attenuated porcine epidemic diarrhea virus strain Zhejiang08 provides effective immune protection attributed to dendritic cell stimulation. Vaccine 35: 7033-7041, 2017.

20. Corazza GR, Frazzoni M and Gasbarrini G: Jejunal intraepithelial lymphocytes in coeliac disease: Are they increased or decreased? Gut 25: 158-162, 1984.

21. Inoue R, Tsukahara T, Nakatani M, Okutani M, Nishibayashi R, Ogawa S, Harayama T, Nagino T, Hatanaka H, Fukuta K, et al: Weaning markedly affects transcriptome profiles and peyer's patch development in piglet ileum. Front Immunol 6: 630, 2015.

22. Ryan KA, Daly P, Li Y, Hooton C and O'Toole PW: Strain-specific inhibition of helicobacter pylori by lactobacillus salivarius and other lactobacilli. J Antimicrob Chemother 61: 831-834, 2008.

23. Youssef S and Salah M: Differential expression of CD3, TNF- $\alpha$, and VEGF induced by olanzapine on the spleen of adult male albino rats and the possible protective role of vitamin $\mathrm{C}$. Biomedicines 7: E39, 2019.

24. Lin J, Tu C, Mou C, Chen X and Yang Q: CpG DNA facilitate the inactivated transmissible gastroenteritis virus in enhancing the local and systemic immune response of pigs via oral administration. Vet Immunol Immunopathol 172: 1-8, 2016.

25. Livak KJ and Schmittgen TD: Analysis of relative gene expression data using real-time quantitative PCR and the 2(-Delta Delta C(T)) method. Methods 25: 402-408, 2001.

26. Kiyono H and Fukuyama S: NALT-versus Peyer's-patch-mediated mucosal immunity. Nat Rev Immunol 4: 699-710, 2004.

27. Sato T, Endoh M, Yoshida H, Yasuo S, Katsuno T, Saito Y, Isono $\mathrm{K}$ and Koseki H: Mammalian Polycomb complexes are required for Peyer's patch development by regulating lymphoid cell proliferation. Gene 379: 166-174, 2006.

28. Lasa-Saracíbar B, Aznar MÁ, Lana H, Aizpún I, Gil AG and Blanco-Prieto MJ: Lipid nanoparticles protect from edelfosine toxicity in vivo. Int J Pharm 474: 1-5, 2014. 
29. Kabat AM, Pott $\mathrm{J}$ and Maloy KJ: The mucosal immune system and its regulation by autophagy. Front Immunol 7: 240, 2016.

30. van Wijk F and Cheroutre $\mathrm{H}$ : Mucosal T cells in gut homeostasis and inflammation. Expert Rev Clin Immunol 6: 559-566, 2010.

31. Wu RQ, Zhang DF, Tu E, Chen QM and Chen W: The mucosal immune system in the oral cavity-an orchestra of T cell diversity. Int J Oral Sci 6: 125-132, 2014.

32. Song D, Moon $\mathrm{H}$ and Kang BJ: Porcine epidemic diarrhea: A review of current epidemiology and available vaccines. Clin Exp Vaccine Res 4: 166-176, 2015.

33. O'Neal CM, Clements JD, Estes MK and Conner ME: Rotavirus $2 / 6$ viruslike particles administered intranasally with cholera toxin, Escherichia coli heat-labile toxin (LT), and LT-R192G induce protection from rotavirus challenge. J Virol 72: 3390-3393, 1998.

34. Van Oirschot JT: Intranasal vaccination of pigs against Aujeszky's disease: Comparison with one or two doses of attenuated vaccines in pigs with high maternal antibody titres. Res Vet Sci 42: 12-16, 1987.

35. Zhang L, Tian X and Zhou F: Intranasal administration of $\mathrm{CpG}$ oligonucleotides induces mucosal and systemic Type 1 immune responses and adjuvant activity to porcine reproductive and respiratory syndrome killed virus vaccine in piglets in vivo. Int Immunopharmacol 7: 1732-1740, 2007.

36. Schijns VE and Lavelle EC: Trends in vaccine adjuvants. Expert Rev Vaccines 10: 539-550, 2011.

37. Blaauboer SM, Mansouri S, Tucker HR, Wang HL, Gabrielle VD and Jin L: The mucosal adjuvant cyclic di-GMP enhances antigen uptake and selectively activates pinocytosis-efficient cells in vivo. Elife 4: 2015.

38. Setlow P: Spores of Bacillus subtilis: Their resistance to and killing by radiation, heat and chemicals. J Appl Microbiol 101: $514-525,2006$

39. Deng J, Li Y, Zhang J and Yang Q: Co-administration of Bacillus subtilis RJGP16 and Lactobacillus salivarius B1 strongly enhances the intestinal mucosal immunity of piglets. Res Vet Sci 94: 62-68, 2013.

40. Yang Y, Jing Y, Yang J and Yang Q: Effects of intranasal administration with Bacillus subtilison immune cells in the nasal mucosa and tonsils of piglets. Exp Ther Med 15: 5189-5198, 2018

41. Jing Y, Liu $\mathrm{H}, \mathrm{Xu} \mathrm{W}$ and Yang Q: Amelioration of the DSS-induced colitis in mice by pretreatment with 4,4'-diaponeurosporene-producingBacillus subtilis. Exp Ther Med 14: 6069-6073, 2017.

42. Herich RJ: Is the role of $\operatorname{IgA}$ in local immunity completely known? Immunol 28: 1-15, 2016.

43. Mantis NJ, Rol N and Corthésy B: Secretory IgA's complex roles in immunity and mucosal homeostasis in the gut. Mucosal Immunol 4: 603-611,2011.

44. Holmgren $\mathrm{J}$ and Czerkinsky C: Mucosal immunity and vaccines. Nat Med 11 (4 Suppl): S45-S53, 2005.

45. Neutra MR and Kozlowski PA: Mucosal vaccines: The promise and the challenge. Nat Rev Immunol 6: 148-158, 2006.
46. Mcghee JR, Fujihashi K, Beagley KW and Kiyono HJ: Role of interleukin- 6 in human and mouse mucosal IgA plasma cell responses. Immunol Res 10: 418-422, 1991.

47. Libbey JE and Fujinami RS: Adaptive immune response to viral infections in the central nervous system. Handb Clin Neurol 123: 225-247, 2014

48. Hershberg R and Blumberg RS: The lymphocyte-epithelial-bacterial interface. Springer US, 2003.

49. Li Z, Zhang C, Zhou Z, Zhang J, Zhang J and Tian Z: Small intestinal intraepithelial lymphocytes expressing CD8 and T cell receptor $\gamma \delta$ are involved in bacterial clearance during Salmonella enterica serovar Typhimurium infection. Infect Immun 80: 565-574, 2012.

50. Dharakul T, Rott L and Greenberg HB: Recovery from chronic rotavirus infection in mice with severe combined immunodeficiency: Virus clearance mediated by adoptive transfer of immune CD8+ T lymphocytes. J Virol 64: 4375-4382, 1990.

51. Vazquez MI, Catalan-Dibene J and Zlotnik AJC: B cells responses and cytokine production are regulated by their immune microenvironment. Cytokine 74: 318-326, 2015.

52. Onyiah JC and Colgan SP: Cytokine responses and epithelial function in the intestinal mucosa. Cell Mol Life Sci 73 4203-4212, 2016

53. Steidler L, Robinson K, Chamberlain L, Schofield KM, Remaut E, Le Page RW and Wells JM: Mucosal delivery of murine interleukin-2 (IL-2) and IL- 6 by recombinant strains of Lactococcus lactis coexpressing antigen and cytokine. Infect Immun 66: 3183-3189, 1998.

54. Weiss ID, Wald O, Wald H, Beider K, Abraham M, Galun E, Nagler A and Peled A: IFN-gamma treatment at early stages of influenza virus infection protects mice from death in a NK cell-dependent manner. J Interferon Cytokine Res 30: 439-449, 2010.

55. Kak G, Raza M and Tiwari BK: Interferon-gamma (IFN- $\gamma$ ): Exploring its implications in infectious diseases. Biomol Concepts 9: 64-79, 2018.

56. Djupesland PG: Nasal drug delivery devices: Characteristics and performance in a clinical perspective-a review. Drug Deliv Transl Res 3: 42-62, 2013.

57. El-Kattan A, Hurst S, Brodfuehrer J and Loi CM: Anatomical and physiological factors affecting oral drug bioavailability in rats, dogs, and humans. John Wiley \& Sons, Inc., 2011.

58. Yen HH, Scheerlinck JP, Gekas S and Sutton P: A sheep cannulation model for evaluation of nasal vaccine delivery. Methods 38 117-123, 2006.

This work is licensed under a Creative Commons Attribution-NonCommercial-NoDerivatives 4.0 International (CC BY-NC-ND 4.0) License. 